http://jmscr.igmpublication.org/home/ ISSN (e)-2347-176x ISSN (p) 2455-0450 crossref DOI: https://dx.doi.org/10.18535/jmscr/v9i5.19

\title{
Prevalence of Disturbed Level of Consciousness in Ischemic Cerebrovascular Stroke Patients Presented to the Emergency Department of Alexandria University Hospital
}

\author{
Authors \\ Mohamed Elsayed Mohamed ${ }^{1}$, Abdel-Fattah Ali El-Qersh², \\ Mohamed Mohamed Hamdy ${ }^{3}$ and Nadia Foad Farghaly ${ }^{4}$ \\ ${ }^{1}$ Emergency Department, Faculty of Medicine University of Alexandria, Egypt \\ ${ }^{2,3}$ Neuropsychiatry Department, Faculty of Medicine, University of Alexandria, Egypt \\ ${ }^{4}$ Public Health, Preventive and Social Medicine, Faculty of Medicine, University of Alexandria, Egypt
}

\begin{abstract}
A study performed on 122 patients diagnosed with ischemic cerebrovascular stroke presented to the Emergency department of Alexandria University hospital during the period from 1/7/2014 to 31/12/2014 in order to study the prevalence of disturbed level of consciousness in this group of patients. Those patients were subjected to history taking, clinical examination, and assessment of the LOC, laboratory investigations and radiological examination using CT-brain and MRI in selected cases.

The most common risk factors were hypertension then Diabetes Mellitus. Males were more affected than female and the mean age of the patients was 59 years and the mean systolic blood pressures of patients were $144 \mathrm{~mm} . \mathrm{Hg}$.

Based on the GCS it was found that $27 \%$ of the patients had DLC. The patients were classified according to the severity of the impairment of the LOC into mild (GCS 14-13), Moderate (GCS 12-9) and Severe (GCS 3-8).Mild cases comprised 36.3\%, moderate $33.3 \%$ and severe $30.3 \%$ of DLC patients.33.3\% of the DLC patients were intubated.

The most important CT-brain finding in the DLC patients was MCA infarction that was found in $45.5 \%$ of DLC patients. Those patients are more labile to develop brain swelling and haemorrhagic transformation. It was found that $40 \%$ of MCA stroke patients were in deep coma.

Infratentorial infarctions also are an important causes for the occurrence of disturbed level of consciousness.

Hypertension is an important risk factor for stroke yet, it was found no significant correlation between hypertension and DLC.

It was found that there was a significant correlation between DLC and the admission hyperglycaemia and hyponatremia. While there was no correlation between raised admission Creatinine level and altered mental status.
\end{abstract}

Keywords: Disturbed level of consciousness, Cerebrovascular stroke, GCS.

\section{Introduction}

Cerebrovascular stroke is the third leading cause of death and a leading cause of long-term disability. Stroke is defined as any vascular injury that reduces the cerebral blood flow to a specific region in the brain causing a neurological 
impairment. Approximately about $87 \%$ of strokes are ischemic in nature.Cerebral ischemia is caused by a reduction in blood flow that lasts longer than several seconds. (Wolf et al., 2011) Disturbed level of consciousness is one of the common presentation encountered in the emergency department of cerebrovascular stroke most of these cases are critical and need intensive interventions and specialized unit in stroke care admission, also it increases the burden of stroke mortality. (Hashem et al.,2004). Possible risk factors for development of disturbed sensorium in ischemic stroke patients include: middle cerebral artery infarction, brain oedema (Takagi et al.,1981), haemorrhagic transformation of ischemic stroke (Paciaroni et al.,2008), hyponatraemia (Rodrigues et al.,2014) and hyperglycaemia (Capes et al.,2001)

\section{Patients}

Patients admitted to the emergency department in Alexandria University hospital during the period $1 / 7 / 2014$ to $31 / 12 / 2014$ and suspected to have cerebrovascular stroke depending on the clinical data and CT brain.

\section{Methods}

\section{Study Design}

A prospective studywas conducted on patients admitted to the emergency department in Alexandria University hospital during the period $1 / 7 / 2014$ to $31 / 12 / 2014$ and suspected to have cerebrovascular stroke depending on the clinical data and CT brain.

\section{Tools of data collection}

The patients in the study was subjected to: 1-History Taking: special emphasize on previous cerebrovascular accidents, intoxication, liver diseases, hypertension and diabetes mellitus.

\section{2-Clinical Examination:}

Examination of the general condition: Airway, breathing and circulation

Neurological examination: Glasgow coma scale, motor and sensory assessment.

\section{3-Investigations}

Laboratory: Random blood Glucose. Arterial Blood Gases analysis.

Serum Urea and Creatinine. Electrolytes: Sodium and Potassium.

Liver Function tests: Bleeding profile, SGOT and SGPT.

\section{ESR and CRP}

CSF analysis in case of suspected meningitis. Radiology: CT-Brain.

MRI brain for selected patients who had their initial CT unremarkable.

4-Discharge sheet of all the patients were revised to estimate the mortality rate.

\section{Statistical Analysis}

Data were analyzed using software (SPSS 21)

Descriptive data was expressed in frequency and percent and was analyzed using Chi-square test also exact tests such Fisher exact and Monte Carlo was applied to compare different groups.

$\mathrm{P}$ value was assumed to be significant at $(0.05)$ with confidence interval set at $95 \%$.

\section{Results}

During the period from $1 / 7 / 2014$ to $31 / 12 / 2014$, 122 ischemic stroke patients were admitted to the emergency department of Alexandria university hospital.

Table 1 shows the demographic characteristic of the ischemic stroke patients admitted to the emergency department where: sixty seven (54.9\%) patients were males, fifty five $(45.1 \%)$ patients were females, and the mean age of the patients was 58 years with $\mathrm{SD} \pm 12$.

According to the past medical history: fifty five (45.1\%) patients were hypertensive, Thirty-six (29.5\%) patients were diabetic, eleven patients (9\%) were Hepatitis C positive patients and three patients $(2.5 \%)$ were Intravenous drugs abusers. Table 2: shows the distribution of the ischemic stroke patients according the systolic blood pressure on admission: forty seven patients (38.6\%) their systolic blood pressures were between $90 \mathrm{~mm} . \mathrm{Hg}$ and less than $140 \mathrm{~mm} . \mathrm{Hg}$, 
sixty-two patients $(50.8 \%)$ their systolic blood pressure between $140 \mathrm{~mm} . \mathrm{Hg}$ and less than 180 $\mathrm{mm}$. $\mathrm{Hg}$ and thirteen patients $(10.6 \%)$ their systolic blood pressure was more than 180 $\mathrm{mm} . \mathrm{Hg}$, the mean systolic blood pressure was 144 mm.Hg with standard deviation \pm 14 .

Table 4: shows the different clinical presentations of ischemic stroke presented to the Emergency department: Motor weakness or lag was present in seventy-four patients (60\%), dysarthria was present in thirty-six patients $(29.5 \%)$, dysphasia and aphasia were present in eleven $(9 \%)$ patients, pure sensory manifestations were present in three patients $(2.45 \%)$ and disturbed level of consciousness was present in 33 patients $(27 \%)$. Table 3 reveals the distribution of patients according to the CT-brain findings: $41 \%$ of cases had subcortical white matter infarction, $22.1 \%$ of cases had basal ganglia infarction, $18.1 \%$ of cases had small cortical infarction, $16.4 \%$ of cases had MCA (middle cerebral artery infarction) infarction, $1.6 \%$ of cases had pontine infarction and $0.8 \%$ of cases had cerebellar infarction. According to the complications of stroke (table 5): five cases presented to the emergency department by brain swelling following ischemic infarction : four cases (3.28\%) following MCA infarction and one case $(0.82 \%)$ following Cerebellar infarction, Two cases of MCA infarction developed haemorrhagic transformation while three cases with non-MCA infarction suffered from early haemorrhagic transformation, One case $(0.82 \%)$ presented by post-stroke seizures, and three cases (2.45\%) had sepsis all three cases had urosepsis. All these cases presented to the emergency department with disturbed level of consciousness.

Table (1) Demographic characteristics of ischemic stroke patients in the emergency department of Alexandria university hospitals

\begin{tabular}{|l|c|c|c|}
\hline & No. & Percent & Mean / SD \\
\hline Age (year) & & & $58 / \pm 12$ \\
\hline Sex & & & \\
\hline Females & 55 & 45.1 & \\
\hline Males & 67 & 54.9 & \\
\hline Medical History & & & \\
\hline Hypertension & 55 & 45.1 & \\
\hline Diabetes Mellitus & 36 & 29.5 & \\
\hline Atrial Fibrillation & 8 & 6.6 & \\
\hline IV drug Abuse & 3 & 2.5 & \\
\hline Hepatitis C positive & 11 & 9 & \\
\hline
\end{tabular}

Table (2): The distribution of the patients according to Systolic B.P. on admission

\begin{tabular}{|l|c|c|}
\hline Systolic B.P. mm.Hg & Frequency & Percent \\
\hline $90-<140$ & 47 & 38.6 \\
\hline $140-<180$ & 62 & 50.8 \\
\hline$>180$ & 13 & 10.6 \\
\hline Total & 122 & 100 \\
\hline Mean S.B.P. & Standard Deviation & \\
\hline $\mathbf{1 4 4}$ & $\mathbf{\pm 2 4}$ & \\
\hline
\end{tabular}

Table (3) Distribution of cases according to initial clinical presentation

\begin{tabular}{|l|c|c|}
\hline Presentation & Number & Percentage \% \\
\hline Motor weakness / Lag & 74 & 60 \\
\hline Dysarthria & 36 & 29.5 \\
\hline Dysphasia/ Aphasia & 11 & 9 \\
\hline Pure Sensory Manifestations & 3 & 2.45 \\
\hline Disturbed level of consciousness & 33 & 27 \\
\hline
\end{tabular}


Table (4) Distribution of ischemic stroke patients admitted to the Emergency Department according to the CT-brain finding

\begin{tabular}{|l|c|c|}
\hline CT brain & No. & Percentage \\
\hline Basal Ganglia Infarction & 27 & 22.1 \\
\hline Cerebellar Infarction & 1 & 0.8 \\
\hline Small Cortical Infarction & 22 & 18.1 \\
\hline MCA infarction & 20 & 16.4 \\
\hline Pontine Infarction & 2 & 1.6 \\
\hline Subcortical White Matter Infarction & 50 & 41.0 \\
\hline
\end{tabular}

Table (5) Distribution of ischemic cerebrovascular stroke patients according to complications

\begin{tabular}{|l|c|c|}
\hline & Number & Percentage \\
\hline $\begin{array}{l}\text { Brain swelling following MCA infarction with } \\
\text { mid line shift less than 4 mm. }\end{array}$ & 1 & 0.8 \\
\hline $\begin{array}{l}\text { Brain swelling following MCA infarction with } \\
\text { mid line shift less than 4 mm. }\end{array}$ & 3 & 2.45 \\
\hline $\begin{array}{l}\text { Haemorrhagic Transformation of MCA } \\
\text { infarction }\end{array}$ & 2 & 1.64 \\
\hline $\begin{array}{l}\text { Haemorrhagic transformation of non-MCA } \\
\text { infarction }\end{array}$ & 3 & 2.45 \\
\hline Brain Swelling following cerebellar infarction & 1 & 0.82 \\
\hline Post-stroke seizures & 1 & 0.82 \\
\hline Sepsis following ischemic infarction & 3 & 2.45 \\
\hline Total & $\mathbf{1 1}$ & $\mathbf{9}$ \\
\hline
\end{tabular}

Table 5shows that 33(27\%) patients suffered from disturbed level of consciousness as a presentation of ischemic cerebrovascular stroke in the Emergency Department.Table 6show distribution of ischemic cerebrovascular stroke patients admittd to the Emergency Department with disturbed level of consciousness: Eighteen $(54.5 \%)$ patients were males and fifteen $(45.5 \%)$ patients were females. The mean age was 59 years with $\mathrm{SD} \pm 15$.Seven patients $(21.2 \%)$ aged less than or equal forty-five and twenty-six patients (78.8\%) aged more than 45 years. The patients were classified according to the GCS in mild (GCS 14-13), moderate (GCS 12-9) and severe (GCS 8-3) disturbed level of consciousness. Twelve (36.3\%) patients had mild disturbed level of consciousness, eleven patients(33.3\%) has moderate disturbed level of consciousness and ten $(30.3 \%)$ patients has severe disturbed level of consciousness. Eleven patients(33.3\%) were intubated. The mean Random blood glucose of these patients was $192 \mathrm{mg} / \mathrm{dl}$ with $\mathrm{SD} \pm 93.9$, the mean creatinine level was $1.13 \mathrm{mg} / \mathrm{dl}$ with $\mathrm{SD} \pm$ 0.47 and the mean sodium level was $131 \mathrm{mmol} / \mathrm{l}$ with SD \pm 7.7 .
According to the admission systolic blood pressure (table 7): sixteen patients $(48.6 \%)$ their systolic blood pressures were between $90 \mathrm{~mm} . \mathrm{Hg}$ and less than $140 \mathrm{~mm} . \mathrm{Hg}$, twelve patients (36.4\%) their systolic blood pressures were between 140 $\mathrm{mm} . \mathrm{Hg}$ and less than $180 \mathrm{~mm} . \mathrm{Hg}$ and five patients $(15.1 \%)$ their blood pressures were more than $180 \mathrm{~mm} . \mathrm{Hg}$.The mean systolic blood pressure was $141 \mathrm{~mm} . \mathrm{Hg}$ with standard deviation \pm 31 .

Table 8: shows that $51.1 \%$ of the disturbed level of consciousness patients their admission systolic blood pressures were more than $140 \mathrm{~mm} . \mathrm{Hg}$ and $65 \%$ of the non-disturbed level of consciousness patients their admission systolic blood pressure were more then $140 \mathrm{~mm} . \mathrm{Hg}$ (P-value=0.209), denoting there is no significant correlation between admission hypertension and the development of disturbed level of consciousness.

According to the admission Random blood glucose of all cases(table 9) fifty eight patients had random blood glucose level (normal 80-140 $\mathrm{mg} / \mathrm{dl}$ ) more than $140 \mathrm{mg} / \mathrm{dl} 36.2 \%$ of them suffered from disturbed level of consciousness (P value $=0.03)$ which is statistically significant. 
According to the admission Creatinine level (table 10) 22 patients (18\%) had creatinine level (normal $0.5-1.2 \mathrm{mg} / \mathrm{dl})$ more than $1.2 \mathrm{mg} / \mathrm{dl} 9 \%$ of them had disturbed level of consciousness $(\mathrm{P}$ value $=$ 0.106).

According to the admission Sodium level (table 10) (normal $135-145 \mathrm{mmol} / \mathrm{l})$ fifty four $(44.3 \%)$ patients their Sodium level was less $135 \mathrm{mmol} / \mathrm{l}$ $38.9 \%$ of them suffered from disturbed level of consciousness, in four patients their Sodium level was more than $145 \mathrm{mmol} / \mathrm{l}$ and only one had disturbed level of consciousness $(25 \%)$. $(\mathrm{P}$ value $=$ 0.022 ) denotes there is a correlation between the Sodium level and the disturbed level of consciousness.

Tables 11,12 show the CT-Brain findings of the disturbed level of consciousness patients:

As it is noted three patients (9\%) had infratentorial infarctions( two patients had pontine infarction and one patient had cerebellar infarction) while the remaining thirty patients had supratentorial infactions :fifteen patients $(45.5 \%)$ had Middle Cerebral Artery Infarction, nine patients $(27.3 \%)$ had subcortical white matter infarction, four patients(12\%) had basal ganglia infarction, two patients $(6.1 \%)$ had cortical infarction

As mentioned before twenty patients had Middle cerebral artery(table 13)infarction $75 \%$ of them suffered from disturbed level of consciousness these patients comprises about $45 \%$ of the total number of disturbed level of consciousness. ( $P$ value $<0.000$ )

Table (14): shows that all the cases of infratentorial infarctions suffered from disturbed level of consciousness ( $\mathrm{P}$ value $=0.0039$ ); this shows there is a significant correlation between the infratentorial infarctions and the development of disturbed level of consciousness.

Table(15):Shows the mortality ratio of ischemic stroke patients admitted to the Emergency department, as it noticed three patients from the non-disturbed level of consciousness patients were dead (3.4\% of the total fully conscious patient) and twelve patients from the disturbed level of consciousness patients were dead $(36.4 \%$ of the total number of the disturbed level of consciousness patients (P-value $=0.000003)$.

Table (6) Distribution of disturbed level of consciousness in ischemic stroke patient admitted to Emergency departement in Alexandria university hospital : demographic, clinical and laboratory characteristics.

\begin{tabular}{|l|c|c|c|}
\hline \multicolumn{1}{|c|}{ Age (year) } & No. & Percentage & Mean / SD \\
\hline Age & & & $59 / \pm 15$ \\
\hline \multicolumn{1}{|c|}{$\leq 45$ years } & & & \\
\hline Sex & 7 & 21.2 & \\
\hline Male & 26 & 78.8 & \\
\hline Femare & 18 & 54.5 & \\
\hline GCS $^{*}$ & 15 & 45.6 & \\
\hline Mild & & & \\
\hline Moderate & 12 & 36.3 & \\
\hline Severe & 11 & 33.3 & \\
\hline Intubation & 10 & 30.3 & \\
\hline Yes & & & \\
\hline No & 11 & $33.3 \%$ & \\
\hline RBG* (mg/dl) & 22 & $67.7 \%$ & \\
\hline Creatinine(mg/dl) & & & $192 / \pm 93.9$ \\
\hline Na (mmol/L) & & & $131 / \pm 7.7$ \\
\hline
\end{tabular}


Table 7: Distribution of the disturbed level of consciousness cases according to the systolic blood pressure

\begin{tabular}{|l|c|c|}
\hline Systolic B.P. mm.Hg & Frequency & Percent \\
\hline $90-<140$ & 16 & 48.5 \\
\hline $140-<180$ & 12 & 36.4 \\
\hline$>180$ & 5 & 15.1 \\
\hline Total & 33 & 100 \\
\hline Mean B.P. & Standard Deviation & \\
\hline $\mathbf{1 4 1}$ & $\mathbf{\pm 3 1}$ & \\
\hline
\end{tabular}

Table 8: Correlation between systolic blood pressure and the level of consciousness

\begin{tabular}{|l|c|c|c|c|c|}
\hline \multirow{2}{*}{ Systolic B.P. } & \multicolumn{2}{|c|}{ No DLC } & \multicolumn{2}{c|}{ DLC } & \multirow{2}{*}{ P-value } \\
\cline { 2 - 5 } & $\mathbf{n}$ & $\mathbf{\%}$ & $\mathbf{n}$ & $\mathbf{\%}$ & \\
\hline$>140$ & 58 & 65 & 17 & 51.5 & \multirow{2}{*}{0.209} \\
\hline$<140$ & 31 & 35 & 16 & 48.5 & \\
\hline
\end{tabular}

*Fisher's Exact test: MC technique.

Table (9)(10) Correlation of random blood glucose, Creatinine level and sodium levelswith the level of consciousness.

\begin{tabular}{|l|c|c|c|c|c|c|}
\hline & \multicolumn{2}{|c|}{ No DLC } & \multicolumn{2}{c|}{ DLC } & \multirow{2}{*}{$\chi^{2}$} & \multirow{2}{*}{ P-value } \\
\cline { 2 - 5 } & n. & \% & n. & \% & & \\
\hline Random Blood Glucose & 52 & 81.2 & 12 & 18.8 & & \\
$\leq 140$ & 37 & 63.8 & 21 & 36.2 & 4.699 & $0.030^{*}$ \\
$>140$ & 76 & 76.0 & 24 & 24.0 & 2.613 & 0.106 \\
\hline Serum Creatinine (mg/dl) & 13 & 59.1 & 9 & 40.9 & \\
$\leq 1.2$ & &
\end{tabular}

$*$ : Statistically significant at $\leq 0.05$

\begin{tabular}{|l|c|c|c|c|c|}
\hline \multirow{2}{*}{ Na (mmol/L) } & \multicolumn{2}{|c|}{ No DLC } & \multicolumn{2}{c|}{ DLC } & \multirow{2}{*}{ P-value $^{*}$} \\
\cline { 2 - 5 } & $\mathbf{n}$ & $\%$ & $\mathbf{n}$ & $\%$ & \\
\hline$<135$ & 33 & 61.1 & 21 & 38.9 & \multirow{2}{*}{$0.022^{* *}$} \\
\hline $135-145$ & 53 & 82.8 & 11 & 17.2 & \\
\hline$>145$ & 3 & 75.0 & 1 & 25.0 & \\
\hline
\end{tabular}

*Fisher's Exact test: MC technique, ${ }^{* *}$ Statistically significant at $\leq 0.05$

Table (11) (12): Distribution of Disturbed level of consciousness level patients according to the CT-brain Finding:

\begin{tabular}{|l|c|c|}
\hline CT-Brain & No. & Percentage \\
\hline Infra-tentorial infarctions & 3 & 9 \\
\hline Supra-tentorial Infarctions & 30 & 91 \\
\hline Total & 33 & 100 \\
\hline
\end{tabular}

\begin{tabular}{|l|c|c|}
\hline CT-Brain & No. & Percentage \\
\hline MCA* Infarction & 15 & 45.5 \\
\hline Subcortical white matter Infarction & 9 & 27.3 \\
\hline Basal Ganglia Infarction & 4 & 12.0 \\
\hline Pontine Infarction & 2 & 6.1 \\
\hline Small Cortical Infarcation & 2 & 6.1 \\
\hline Cerebellar Infarction & 1 & 3 \\
\hline Total & 33 & 100 \\
\hline
\end{tabular}


Table (13): Middle Cerebral Artery Infarction and relation to disturbed level of consciousness

\begin{tabular}{|c|c|c|c|c|c|c|}
\hline & \multicolumn{4}{|c|}{ Disturbed Level of Consciousness } & \multirow{3}{*}{$\chi^{2}$} & \multirow{3}{*}{$\mathbf{p}$} \\
\hline & \multicolumn{2}{|c|}{$\begin{array}{c}\text { No } \\
(n=89)\end{array}$} & \multicolumn{2}{|c|}{$\begin{array}{c}\text { Yes } \\
(n=33)\end{array}$} & & \\
\hline & n. & $\%$ & n. & $\%$ & & \\
\hline \multirow{3}{*}{$\begin{array}{l}\text { Middle Cerebral } \\
\text { Artery Infarction } \\
\text { No } \\
\text { Yes }\end{array}$} & & & & & \multirow{3}{*}{27.874} & \multirow{3}{*}{$<0.000^{*}$} \\
\hline & 84 & 82.4 & 18 & 17.6 & & \\
\hline & 5 & 25.0 & 15 & 75.0 & & \\
\hline
\end{tabular}

Table 14 : Correlation between the infratentorial infarctions and the disturbed level of consciousness

\begin{tabular}{|c|c|c|c|c|c|c|}
\hline & \multicolumn{4}{|c|}{ Disturbed Level of Consciousness } & \multirow{3}{*}{$\chi^{2}$} & \multirow{3}{*}{$\mathbf{p}$} \\
\hline & \multicolumn{2}{|c|}{$\begin{array}{c}\text { No } \\
(\mathbf{n}=\mathbf{8 9}) \\
\end{array}$} & \multicolumn{2}{|c|}{$\begin{array}{c}\text { Yes } \\
(\mathbf{n}=\mathbf{3 3}) \\
\end{array}$} & & \\
\hline & n. & $\%$ & n. & $\%$ & & \\
\hline $\begin{array}{l}\text { Infratentorial infarctions } \\
\text { No } \\
\text { Yes }\end{array}$ & $\begin{array}{c}89 \\
0\end{array}$ & $\begin{array}{c}100 \\
0\end{array}$ & $\begin{array}{c}30 \\
3\end{array}$ & $\begin{array}{c}91 \\
9\end{array}$ & 8.295 & $0.0039 *$ \\
\hline
\end{tabular}

Table (15): Correlation between the disturbed level of consciousness and the mortality rate of patients:

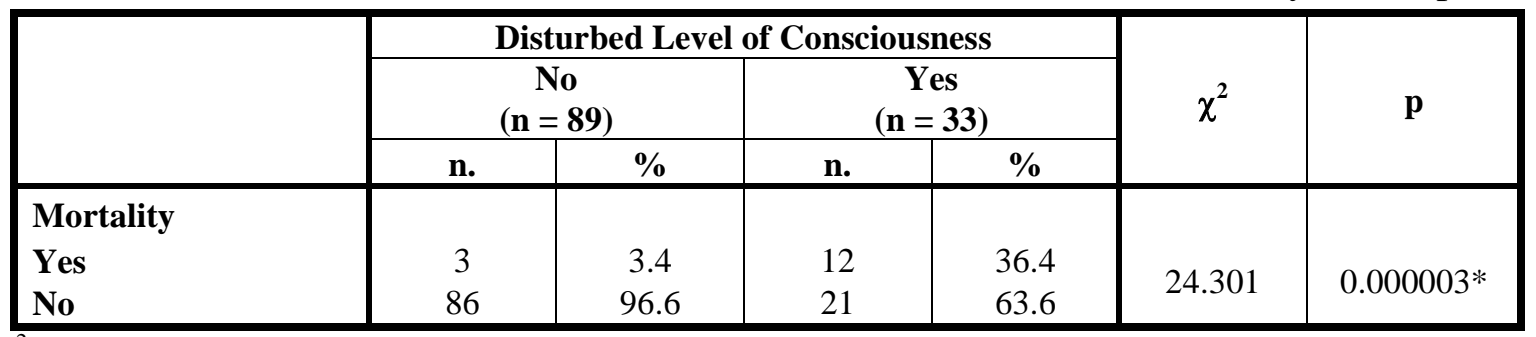

$\chi^{2}$ : Chi square test

*: Statistically significant at $\leq 0.05$

\section{Discussion}

During the period from $1 / 7 / 2014$ to $31 / 12 / 2014$ 122 patients diagnosed in the emergency department of Alexandria university hospital with ischemic cerebrovascular stroke. We noticed that percentage of males more than females $(54.9 \%$ for male vs $45.1 \%$ for females) this results similar to that reported by Giacomini et al and Gillum et al they reported than $60 \%$ of the ischemic stroke patients were males.( Giacomini et al.,1996)

The mean age of patients was 58 years this was younger than reported by White et al. as the mean age of patients was 70 years among different ethnic groups.(White et al.,2005)
We observed that $45 \%$ of cases were hypertensive, $29 \%$ of cases were diabetics and $6.6 \%$ of cases had Atrial fibrillation; according toGrau et al. Hypertension remains the most common risk factor where $66 \%$ of patients were hypertensive, diabetes comprises about $28 \%$ of cases and $26 \%$ of patients had atrial fibrillation.(Grau et al.,2001) Williams M. et al reported that old age is a risk factor for atrial fibrillation $70 \%$ of patients are older than 75 years (Williams et al., 2002), according to Abbott et al the attributable risk of atrial fibrillation increased, rising from $1.5 \%$ for those aged $50-59$ years to $23.5 \%$ for those aged 80-89 years (Abbott et al.,1991); as mentioned before in this study the mean age of patients was 58 years. 
Regarding the clinical presentation in the Emergency department: motor weakness or lag is the most common initial clinical presentation it was found in $60 \%$ of the cases with or without other clinical manifestations.Dysathria is the second common presentation was present in 30\% of the cases also associated with other clinical manifestations or sole presentation.Pure sensory manifestation were present in $2.45 \%$; dysphasia and aphasia in $9 \%$ of the cases.Disturbed level of consciousness was noticed in $27 \%$ of the patients. CT-brain was done to all cases: Basal Ganglia infarctions were found in about $22.1 \%$ of patients,sub-coritcal white matter infarctions in $41 \%$, middle cerebral artery infarction in $16.4 \%$,small cortical infarctions in $18 \%$,cerebellar infarction in $0.8 \%$ and pontine infarction in $1.6 \%$. Regarding complications of stroke it was noticed that $4 \%$ of cases suffered from early haemorrhagic transformation of ischemic stroke; all these cases are associated with rapid deterioration of the level of consciousness, none of these cases was subjected to thrombolytic treatment.Paciaroni et alstated that about $9 \%$ of ischemic cerebrovascular stroke suffer from early haemorrhagic transformation while $3 \%$ of patients undergo deterioration of the clinical course;some cases underwent thrombolytic treatment and hemorrhagic transformation occurred as a complication. (Paciaroni et al.,2008)

Brain swelling is a serious complication following Middle Cerebral Artery infarction and cerebellar infarction, it was noticed that $3.2 \%$ of cases had brain swelling following MCA infarction and $0.8 \%$ of cases had swelling complicating cerebellar infarction, we noticed that $20 \%$ of patients with MCA infarction suffered from brain swelling.Similar results were reported byHeinsius et al.(Heinsius et al.,1998)

All cases in the srtudy were subjected to assessment of level of consciousness using the Glascow Coma Scale, patient considered to have disturbed level of consciousness if Glascow Coma Scale was less than 15 . We noticed that $27 \%$ of patients suffered from disturbed level of consciousness , $21 \%$ of them $(n=7)$ aged younger than or equal 45 years; $54 \%$ of cases were males and $46 \%$ were female.The patients were classified in-to:mild (GCS 14-13), moderate(GCS12-9) and severe (GCS8-3) disturbed level of consciousness; mild category comprised about $36.3 \%$ of the disturbed level of consciousness patient, moderate $33.3 \%$ and severe $30.3 \%$; those patients in severe category considered to be in deep coma and all of them required intubation and assissted ventilation. Bogousslavsky et al reported that about disturbed level of consciousness was the first presentation in $13-15 \%$ of the ischemic cerebrovascular stroke patients.(Bogousslavsky et al.,2007).33\% of the patients with disturbed level of consciousness were intubated and mechanically ventilated due to aspiration and deep coma;similar data were reported by Hassan et al. they mentioned that The circumstances surrounding mechanical ventilation were aspiration and generalized tonic clonic seizures or status epilepticus (Hassan et al.,2012), progression to stupor and inability to protect the airway from brain swelling. In this study : all cases of brain swelling that complicated cerebellar infarction $(n=1)$ and $75 \%$ of brain swelling following MCA infarction $(n=3)$ needed intubation to secure their airway.One case developed status epilepticus following stroke and was intubated.

According to the admission systolic blood pressure: it was noticed that the mean Systolic Blood pressure of all ischemic stroke patients presented to the emergency department was 144 mm.Hg with $\mathrm{SD} \pm 24$, while the mean systolic blood pressure of the disturbed level of consciousness group was $141 \mathrm{~mm} . \mathrm{Hg}$ with SD \pm $31.65 \%$ of the non-disturbed level of consciousness patients their admission systolic blood pressure was more than $140 \mathrm{~mm} . \mathrm{Hg}$, while $51.5 \%$ of the disturbed level of consciousness their admission systolic blood pressure was more than $140 \mathrm{~mm} . \mathrm{Hg}, \mathrm{P}$-value $=0.209$, denotes that their no significant correlation between admission systolic hypertension and disturbed level of consciousness. 
Regarding the CT-brain finding of the impaired level of consciousness patients it was found that $45.5 \%$ of patients had MCA infarction , $27.3 \%$ had subcortical white matter infarction , $12 \%$ has Basal Ganglia infarction, $6.1 \%$ had Cortical infarction, $6.1 \%$ had Pontine infarction and 1\% had Cerebellar infarction.We concluded that Middle Cerebral artery infarction(MCA) was a very important CT-brain finding in this study: it was noticed that $16 \%$ of the patients suffered from MCA infarction from the total number of patients presented to the emergency department; $75 \%$ $(n=15)$ of them suffered from disturbed level of consciousness and this comprises about $45 \%$ of the total number of disturbed level of consciousness patients in our study ( $\mathrm{P}$ value < 0.000 ), there is singificant association between the MCA artery infarction and the development of the disturbed level of consciousness in such patients.This large stroke makes the brain tissue more labile to swelling and hemorrhagic transformation, as mentioned before: brain swelling was noticed in about $20 \%$ of the MCA stroke. $40 \%$ of MCA stroke patients with disturbed level of consciousness $(n=8)$ developed deep coma and needed intubation and mechanical ventilation to secure their airway.It was noticed that $37.5 \%(n=3)$ of these patients had brain swelling with midline shift more than $4 \mathrm{~mm}$. and $25 \%$ of them had hemorrhagic transformation that also impacted an mass effect with midline shift more than $4 \mathrm{~mm}$. Oxbury et al indicated that middle cerebral artery infarction is an important cause of impaired level of consciousness,commonly produces fatal brain edema and makes the prognosis much worse. (Oxbury et al.,1981) Takagi et al stated that there is a significant relation between large volume infarction and the development of impaired level of consciousness. (Takagi et al.,1994)

The infratentorial infarctions comprised about $2.5 \%$ of the all the number of admitted ischemic stroke patients all of them suffered from disturbed level of consciousness and they were found in $9 \%$ of the disturbed level of consciousness patients $(\mathrm{P}-$ value $=0.0039$ ) denotes there is a singificant correlation between the infratentorial infarctions and altered level of consciousness.All patients suffered from infratentorial infarctions were in deep coma and intubated;the one patient suffered from cerebellar infarction developed cerebellar swelling. Hornig et alstated that cerebellar swelling due to infarction has delerious effect on the level of consciousness and emergency decompressive craniotomy is the treatment of choice.(Hornig et al.,1994)

Regarding the admission Glucose level: It was mentioned previously that Hyperglycemia makes the clinical outcome worse regardless of the presence of pre-existing diabetes mellitus it is associated with poor recovery and increased mortality.The mean admission random blood glucose level of the disturbed level of consciousness patient was $192 \mathrm{mg} / \mathrm{dl}$ while that of the non-disturbed level of consciousness was 175 $\mathrm{mg} / \mathrm{dl}(\mathrm{P}$-value $=0.030)$, so there is a significant assocation between hyperglycemia and the impairement of the level of consciousness.

Regarding the serum Sodium level it was found that $44.3 \%(n=54)$ of patients their Sodium level was less than $135 \mathrm{mmol} / \mathrm{l}$ and $38.9 \%(\mathrm{n}=21)$ of them suffered from disturbed level of consciousness $(\mathrm{P}$-value $=0.022)$. The mean Sodium level of the disturbed level of consciousness patients was $131 \mathrm{mmol} / \mathrm{dl}(\mathrm{SD} \pm 7.7)$. There is significant correlation between hyponatremia and development of disturbed level of consciousness. Rodrigues et al. observed that hyponatraemia was present in $16 \%$ of the ischemic stroke patients; they found that those patients had more severe manifestations and with poor clinical outcome. (Rodrigues et al.,2014)

Regarding the serum Creatinine level:KorenMorag et almentioned that Mild degrees of renal dysfunction are associated with increased risk of ischemic stroke.(Koren-Morag et al.,2006)It was found that $18 \%$ of the patients $(n=22)$ had Creatinine level more than $1.2 \mathrm{mg} / \mathrm{dl} ; 40.9 \%$ ( $=$ 9) had disturbed level of consciousness (Pvalue $=0.106$ ). The mean Creatinine level of 
disturbed level of consciousness group was 1.1 $\mathrm{mg} / \mathrm{dl}$ ( $\mathrm{SD} \pm 0.47 \mathrm{mg} / \mathrm{dl}$ ), it was concluded that there is no statistical singificance between the raised Creatinine level and the development of impaired level of consciousness.

The overall mortality rate was $12.3 \%$. The mortality rate was significantly much higher in the disturbed level of consciousness patients : $36.4 \%$ vs $3.4 \%$ in the non disturbed level of consciousness group.P-value $=0.000003$, so we concluded that disturbed level of consciousness in ischemic stroke patients had a negative impact and a significant risk factor in terms of mortality. Kolominsky-Rabas et al reported that Overall inhospital mortality was $4.9 \%$, they reported several risk factors namely: status epilepticus, pneumonia and increased intracranial pressure. (KolominskyRabas et al.,2004)

\section{Conclusion}

Ischemic Cerebrovascular stroke is one the important critical clinical condition that presents to the emergency department with significant effect on morbidity and mortality.

Disturbed level of consciousness is a common presentation of ischemic cerebrovascular stroke and it increases the burden of mortality and morbidity.

It was found the MCA infarctions and it's complication like brain swelling and haemorrhagic transformation were the most common etiology of disturbed level of consciousness in ischemic stroke patients.

Infra-tentorial infarctions although they are rare, they have an important impact in the ocurrence of disturbed level of consciousness.

Other factors like: admission hyperglycemia regardless the patient is diabetic or not and admission hyponatremia played an important role in the development of disturbed level of consciousness of ischemic stroke patient.

\section{References}

1. Abbott RD, Kannel WB. Atrial fibrillation as an independent risk factor for stroke: the Framingham Study. Stroke. 1991;22(8):983-8.

2. Capes SE, Hunt D, Malmberg K, Pathak P, Gerstein HC. Stress Hyperglycemia and Prognosis of Stroke in Nondiabetic and Diabetic Patients: A Systematic Overview. Stroke. 2001;32(10):2426-32.

3. Carrera E, Maeder-Ingvar M, Rossetti AO, Devuyst G, Bogousslavsky J. Trends in Risk Factors, Patterns and Causes in Hospitalized Strokes over 25 Years: The Lausanne Stroke Registry. Cerebrovascular Diseases. 2007;24(1):97103.

4. Giacomini MK. Gender and ethnic differences in hospital-based procedure utilization in California. Archives of Internal Medicine. 1996;156(11):1217-24.

5. Grau AJ, Weimar C, Buggle F, Heinrich A, Goertler M, Neumaier S, et al. Risk Factors, Outcome, and Treatment in Subtypes of Ischemic Stroke: The German Stroke Data Bank. Stroke. 2001;32(11): 2559-66.

6. Hashem S, Fathy H, Elsayed M, Hassan R, Samir H, Kamal M. Outcome and prognosis after ischemic stroke. Egypt J Neurol PsychiatNeurosurg. 2004;41:195212.

7. Heinsius T, Bogousslavsky J, Van Melle G. Large infarcts in the middle cerebral artery territory. Etiology and outcome patterns. Neurology. 1998;50(2):341-50.

8. Heuschmann PU, Kolominsky-Rabas PL, Misselwitz B, et al. Predictors of inhospital mortality and attributable risks of death after ischemic stroke: The german stroke registers study group. Archives of Internal Medicine. 2004;164(16):1761-8.

9. Hornig CR, Rust DS, Busse O, Jauss M, Laun A. Space-occupying cerebellar infarction. Clinical course and prognosis. Stroke. 1994;25(2):372-4.

10. Koren-Morag N, Goldbourt U, Tanne D. Renal dysfunction and risk of ischemic 
stroke or TIA in patients with cardiovascular disease. Neurology. 2006;67(2):224-8.

11. Oxbury JM, Greenhall RC, Grainger KM. Predicting the outcome of stroke: acute stage after cerebral infarction. BMJ. 1975;3(5976):125-7.

12. Rodrigues B, Staff I, Fortunato G, McCullough LD. Hyponatremia in the Prognosis of Acute Ischemic Stroke. Journal of Stroke and Cerebrovascular Diseases.23(5):850-4.

13. Takagi S, Shinohara Y. Internal carotid occlusion: volume of cerebral infarction, clinical findings, and prognosis. Stroke. 1981;12(6):835-9.

14. White H, Boden-Albala B, Wang C, Elkind MSV, Rundek T, Wright CB, et al. Ischemic Stroke Subtype Incidence Among Whites, Blacks, and Hispanics: The Northern Manhattan Study. Circulation. 2005;111(10):1327-31.

15. Williams LS, Rotich J, Qi R, Fineberg N, Espay A, Bruno A, et al. Effects of admission hyperglycemia on mortality and costs in acute ischemic stroke. Neurology. 2002;59(1):67-71. 